Mol. Cryst. Liq. Cryst., Vol. 324, pp. 169-176 Reprints available directly from the publisher Photocopying permitted by license oniy
(O 1998 OPA (Overseas Publishers Association) N.V.

Published by license under the Gordon and Breach Science

Publishers imprint.

Printed in Malaysia.

\title{
Electron Transfer in Porphyrin Multimolecular Self-Organized Nanostructures
}

\section{EDUARD I. ZENKEVICH', SERGEI M. BACHILO', ALEXANDER M. SHULGA ${ }^{1}$, ULRICH REMPEL ${ }^{2}$, ANDREAS WILLERT ${ }^{2}$, CHRISTIAN VON BORCZYSKOWSKI ${ }^{2}$}

Institute of Molecular and Atomic Physics, Acad. Sci. of Belarus, 220072 Minsk, Belarus

2Institut fbr Physik, Technische Universitat Chemnitz, 09107 Chemnitz, Germany

On the base of of covalent and non-covalent bonds nanoscale selfassembling multiporphyrin arrays with well-defined geometry, the controllable number of interacting components and their spectral and photophysical properties were formed. The deactivation of excited singlet and triplet states was studied using steady-state, time-resolved picosecond fluorescence $\left(\Delta_{1 / 2} \approx 30 \mathrm{ps}\right)$ and femtosecond pump-probe $\left(\Delta_{1 / 2} \approx\right.$ $280 \mathrm{fs}$ ) spectroscopy in solvents of various polarity at 77-300 K. It has been found that the competition between the non-radiative energy transfer (within $\leq 10 \mathrm{ps)}$ ) and charge transfer (within $300 \mathrm{fs}-700 \mathrm{ps}$ ) processes in the systems depends on the structure, spectral and redox properties of interacting subunits and may be driven by the distance, temperature and solvent polarity. The possible pathways and mechanisms of the electron transfer in the systems of various types are discussed (Marcus theory for the "normal" region and the non-adiabatic case,. the "superexchange" mechanism).

Keywords Electron transfer, porphyrin dimers, fluorescence quenching, electron acceptors

\section{INTRODUCTION}

During the past decade the majority of supramolecular porphyrin arrays have been used quite intensively in order to model energy and electron 
transfer (ET) processes taking place in vivo ${ }^{[1-3]}$ or to gain insight into the principal possibilities of molecular electronics ${ }^{[4]}$. Apart from covalent linking the desired supramolecular subunits the strategy of self-assembly, using different kinds of non-covalent linkage of the subunits, has attracted a lot of interest ${ }^{[5]}$. Recently, we applied the complexation of $\mathrm{Zn}$ porphyrin chemical dimers by pyridyl-substituted porphyrins as extraligands to form triadicl[] or even pentadic[7] porphyrin arrays. Complexation constants of the order of $10^{6}$ to $10^{7} \mathrm{M}^{-1}$ were found for this two-point self-assembly effect ${ }^{[6]}$.

In the present paper we carry out the comparative analysis of the electronic excitation deactivation processes for the elucidation of the main ET pathways in some multicomponent systems based on $\mathrm{Zn}$ octaethylporphyrin chemical dimer with a phenyl spacer, ( $\mathrm{ZnOEP}) \mathrm{Ph}(\mathrm{ZnOEP})$ which, in its turn, is covalently linked in mesoposition to various electron acceptors [p-benzoquinone (Q) or pyromellitimide $(\mathrm{Im})]$ and/or is self-assembled with tetrapyrrolic extraligands such as dipyridyl substituted porphyrin (P) or dipyridylpentafluor-substituted porphyrin $\left(\mathrm{P}_{\mathrm{F}}\right)$. The corresponding structures of the systems are presented below. In addition to steady-state data, the time-resolved dynamics of electronic excited states deactivation was studied. Fluorescence experiments were carried out using laser picosecond fluorescent setup with 2-D (wavelength-time) registration based on a dye laser (repetition rate $4 \mathrm{MHz}, 10$ ps pulses) and a StreakScope (Hamamatsu Model C4334, $\Delta_{1 / 2} \approx 30 \mathrm{ps}$ ). Pump-probe experiments involved a Coherent MIRA 900 Ti:sapphire laser with a regenerative amplifier and a parametric oscillator running at $1 \mathrm{kHz}$. Excitation in the $400-800 \mathrm{~nm}$ range was used, the experimental response was $\Delta_{1 / 2} \approx 280 \mathrm{fs}$. 


\section{EXPERIMENTAL FINDINGS AND DISCUSSION}

\section{ET in (ZnOEP)Ph(ZnOEP) with covalently linked acceptors}

At $295 \mathrm{~K}$ in toluene the (ZnOEP) Ph(ZnOEP) dimers with $\mathrm{Q}$ and Im have the same absorption and fluorescence spectra with respect to those for the pure dimer, but the fluorescence is essentially quenched and $S_{1}$ state lifetime is found to be $21 \mathrm{ps}$ for $\mathrm{Q}$ and $\sim 60 \mathrm{ps}$ for Im. Increasing the environment polarity (addition of acetone) accelerates the $\mathrm{Zn}$-dimer fluorescence quenching in the case of $Q$ but does not influence on the observed quenching for Im. Pump-probe experiments show that for the system ( $\mathrm{ZnOEP}) \mathrm{Ph}(\mathrm{ZnOEP})$-Im the $\mathrm{Im}^{-}$radical absorption band at $\sim 715 \mathrm{~nm}$ appears (Fig. 1) as a result of the $\mathrm{Zn}$-dimer $\mathrm{S}_{1}$-state quenching and decays with lifetime of $\sim 100$ ps. Together with the $715 \mathrm{~nm}$ band a weaker absorption at $\sim 660 \mathrm{~nm}$ is detected, that corresponds to the ( $\mathrm{ZnOEP}) \mathrm{Ph}(\mathrm{ZnOEP})^{+}$radical. On the base of kinetic data, redox properties and structural parameters of the systems it was shown that Im is a weaker electron acceptor that $\mathrm{Q}$, and ET from the dimer to both acceptors is described by Marcus theory [8] (the "normal" region, the non-adiabatic case, the electronic coupling term $V<200 \mathrm{~cm}^{-1}$ ). These results were used for the analysis of ET processes between large tetrapyrrole subunits in more complex systems.

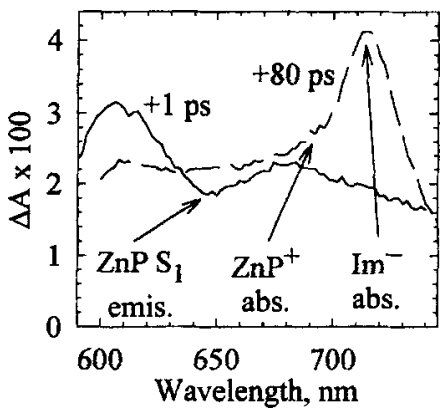

FIGURE 1. Transient absorption spectra of (ZnOEP)Ph(ZnOEP)Im at $295 \mathrm{~K}$ in toluene. 


\section{ET in the Triad Containing (ZnOEP)Ph(ZnOEP)-Q and P Extra-Ligand} In non-polar methylcyclohexane at $295 \mathrm{~K}$ the two-point interaction of $\mathrm{P}$ extra-ligand with the $\mathrm{Zn}$-dimer having a covalently linked $\mathrm{Q}$ leads to the formation of the triadic self-assembled complex (Fig. 2). In this case the additional fluorescence quenching of the ( $\mathrm{ZnOEP}) \mathrm{Ph}(\mathrm{ZnOEP})-\mathrm{Q}$ subunit is observed with an efficient fluorescence sensitization effect for $P$. The derived results show that the $\mathrm{Zn}$-dimer fluorescence quenching ( $\tau_{\mathrm{s}} \leq 1 \mathrm{ps}$ ) is due to the effective $\mathrm{S}-\mathrm{S}$ energy transfer $\mathrm{Zn}$-dimer $\rightarrow \mathrm{P}$ with the probability $\mathrm{F} \geq 7 \cdot 10^{10} \mathrm{~s}^{-1}$ and to ET process $\mathrm{Zn}$-dimer $\rightarrow \mathrm{Q}$. Thus, the energy transfer and ET from $\mathrm{Zn}$-dimer to $\mathrm{P}$ is faster than the considered above ET process from $\mathrm{Zn}$-dimer to $\mathrm{Q}$. Nevertheless, the interaction of the excited states of $\mathrm{Zn}$-dimer and $\mathrm{P}$ is followed by the $\mathrm{P} \mathrm{S}_{1}$-state formation. It is noteworthy that the extra-ligand $P$ fluorescence lifetime shortening from $\tau_{\mathrm{s} 0}=11 \mathrm{~ns}$ to $\tau_{\mathrm{s}}=460 \mathrm{ps}$ is observed, and this process becomes faster in more polar medium and slower at low temperatures The observed facts are attributed to the photoinduced ET via the "superexchange" mechanism where a "spectator" CT state of the triad, $\mathrm{H}_{2} \mathrm{P}^{+}-(\mathrm{Zn} \text {-dimer })^{-}-\mathrm{Q}$, mediates the direct ET from $\mathrm{P}$ to a distant $\mathrm{Q}$ $(R \approx 17.5-19$ E) resulting in the efficient charge transfer within the nonadiabatic limit $t^{[9]}$.

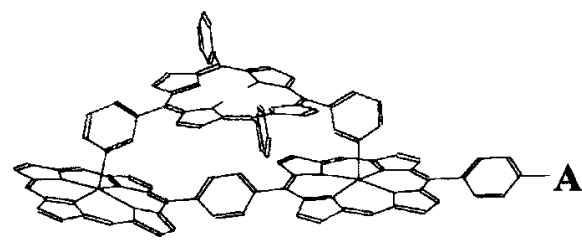

FIGURE 2. Computer-simulated structures of self-organized triads with the covalently linked acceptor A. $\mathbf{A}: \mathrm{CH}_{2}-\mathrm{Q}$ or $\mathrm{CH}_{2}$-Im. 


\section{ET in the Triad Containing (ZnOEP)Ph(ZnOEP)-Im and P Extra-Ligand} In the triad the ultrafast quenching of the $\mathrm{Zn}$-dimer $\mathrm{S}_{1 \text {-state is also }}$ observed with $\tau \approx 1$ ps (Fig. 3) accompained by the $P$ ground state absorption bleaching. However, the ground state absorption of the $\mathrm{Zn}$ dimer does not recover simultaneously. Thus, the $\mathrm{Zn}$-dimer $\mathrm{S}_{1 \text {-state }}$ depopulates due to the efficient ET from $\mathrm{Zn}$-dimer to $\mathrm{P}$ mainly. The following formation of $\mathrm{P} \mathrm{S}_{1}$-state and the $\mathrm{Zn}$-dimer ground state recovering are observed within $5-100 \mathrm{ps.} \mathrm{In} \mathrm{contrast} \mathrm{to} \mathrm{the} \mathrm{similar} \mathrm{triad}$ with $\mathbf{Q}$, the $\mathbf{P}$ fluorescence quenching is weak and its $\mathrm{S}_{1}$-state decay in a ns time scale. Consequently, a distant ET from $P$ to the weaker electron acceptor $\mathrm{Im}$ is essentially slower than in the case of $\mathrm{Q}$.

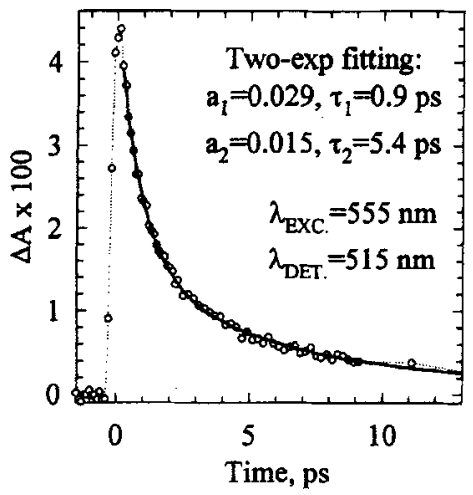

FIGURE 3. Transient absorption kinetics of the triad containing Im and $\mathrm{P}$ in toluene at $295 \mathrm{~K}$. The decay fit is shown by solid line.

\section{ET in the Triad Containing ( $\mathrm{ZnOEP}_{\mathrm{n}} \mathrm{Ph}\left(\mathrm{ZnOEP}_{\mathrm{n}}\right)$ and $\mathrm{P}_{\mathrm{F}}$ or $\mathrm{P}$ Extra-}

\section{Ligands}

These triads are characterized by similar structures (Fig. 4) differing by the nature of the extra-ligand $\left(P\right.$ or $\left.P_{F}\right)$. For the triad formed with $P$, the competition between S-S energy transfer and ET from the $\mathrm{Zn}$-dimer to $\mathrm{P}$ is observed upon the excitation of the former. Upon excitation into the $P$ 
absorption band at $645 \mathrm{~nm}$ its fluorescence intensity is about twice lower in the triad as compared to that for individual $P$ at the same concentration. Nevertheless, time-resolved fluorescence data show no indication of any pronounced porphyrin free base lifetime shortening (7.9 ns) in the triad. This means that the $P S_{1}$-state quenching is negligible similar to the case of the triad with covalently linked Im.

In the case of the triad formed with $\mathrm{P}_{\mathrm{F}}$ (stronger electron $\mathbf{A}$ than $\mathrm{P}$ ) ET is observed even from the excited $P_{F}$ and the charge separated state $\mathrm{PF}_{\mathrm{F}}{ }^{+} \mathrm{Zn}$-dimer ${ }^{-}$is detected (Fig. 5). It reveals that the ultrafast ET with $\mathrm{k}_{\mathrm{ET}} \geq 10^{12} \mathrm{~S}^{-1}$ at $295 \mathrm{~K}$ competes with the S-S energy transfer and results in the strong fluorescence quenching of both $\mathrm{Zn}$-dimer and $\mathrm{P}_{\mathrm{F}}$ subunits. This ET process remains very efficient yet at $120 \mathrm{~K}$. In addition, at $77 \mathrm{~K}$ fluorescence excitation spectra of the system upon the registration in the vibronic band of $P_{F}(\lambda \geq 750 \mathrm{~nm})$ show the noticeable sensitization effect, that is the dimer excited $S_{1}$-state deactivation (within $\leq 10 \mathrm{ps}$ ) is due to both ET and the energy transfer. This explanation is consistent with the conclusions made for covalently linked porphyrin diads (intercenter distance $\mathrm{R}=18.7 \mathrm{~A}^{0}$ ) containing fluorinated porphyrin ${ }^{[10]}$. But in our case, because of smaller $R=8.2 \mathrm{~A}^{0}$ the vectorial interporphyrin $E T$ is faster essentially in the comparison with that for the porpphyrin P-PF diad[10] where $\mathrm{k}_{\mathrm{ET}}=4.1 \cdot 10^{7} \mathrm{~s}^{-1}$. Pump-probe experiments show that the charge separated state transforms within $\sim 2 \mathrm{~ns}$ to the long-lived $\mathrm{P}_{\mathrm{F}} \mathrm{T}_{1}$-state (Fig. 5). Upon the equivalent excitation conditions at $\lambda_{e x}=532 \mathrm{~nm}$ the triplet state parameters of $\mathrm{P}_{\mathrm{F}}\left(\tau \mathrm{\tau} \approx 350 \mathrm{~ns}\right.$ in the presence of $\mathrm{O}_{2}, \mathrm{~T}-\mathrm{T}$ absorption amplitude) for the ( $\mathrm{ZnOEP}) \mathrm{Ph}(\mathrm{ZnOEP})-\mathrm{P}_{\mathrm{F}}$ triad are close to those for the ( $\mathrm{ZnOEP}) \mathrm{Ph}(\mathrm{ZnOEP})-\mathrm{P}$ triad at the same concentrations. It means that the intermediate $\mathrm{PF}_{\mathrm{F}}{ }^{+}-\mathrm{Zn}$-dimer ${ }^{-}$radical-ion state is presumed to be higher than the extra-ligand $P_{F}$ triplet state. 


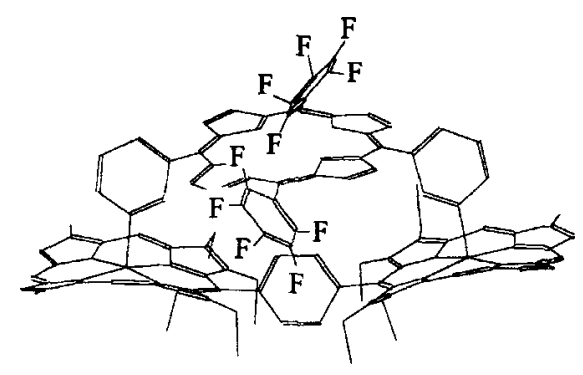

FIGURE 4. Computer-simulated structure of the self-organized triad with $\mathrm{P}_{\mathrm{F}}$ extra-ligand.

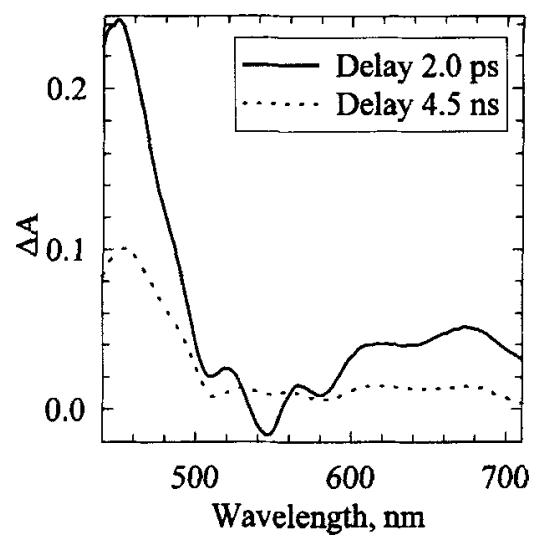

FIGURE 5. Transient absorption spectra of the triad with $\mathrm{P}_{\mathrm{F}}$ in toluene at two delays, $\mathrm{T}=295 \mathrm{~K}$.

Acknowledgments. The financial support from the National Foundation for Basic Research of Belarus (Grant Nr. Ph 96-92) and VolkswagenStiftung (Grant Nr. I/72 171) is gratefully acknowledged.

\section{References}

[1.] M.R. Wasielewski, Chem. Rev., 92, 435 (1992).

[2.] A. Osuka, S. Marumo, N. Mataga, S. Taniguchi, T. Okada, I. Yamazaki, Y. Nishimura, T. Ohno and K. Nozaki, J. Amer. 
Chem. Soc., 118, 155 (1996).

[3.] A. Harriman and J.P. Sauvage, Chem.Soc.Rev., 25, .41 (1996).

[4.] V. Balzani and F. Scandola, Supramolecular Photochemistry (Ellis Horwood, New York/ London/ Toronto/ Sydney/Tokyo/ Singapore, 1991).

[5.] H.J. Schneider and H. Durr (Eds.), Frontiers in Supramolecular Organic Chemistry and Photochemistry (Verlag Chemie, Weinheim, 1991).

[6.] A.V. Chernook, A.M. Shulga, E.I. Zenkevich, U. Rempel and $\mathrm{Ch}$. von Borzcyskowski, J. Phys. Chem., 100, 1918 (1996).

[7.] A.V. Chernook, U. Rempel, Ch. von Borczyskowski, E.I. Zenkevich and A.M. Shulga, Chem. Phys. Lett., 254, 229 (1996).

[8.] R.A. Marcus, Rev. Modern Phys., 65, 599 (1993).

[9.] M. Bixon, J. Jortner and M.E. Michel-Beyerle, Biochim. Biophys. Acta, 1056, 116 (1991).

[10.] J.M. DeGraziano, P.A. Liddell, L. Leggett, A. Moore, T. Moore and D. Gust, J. Phys. Chem., 98, 1758 (1994). 